\title{
Laboratory diagnosis of cryptosporidiosis
}

\author{
DP CASEMORE, ${ }^{*}$ M ARMSTRONG,${ }^{*}$ RL SANDS $\dagger$
}

\begin{abstract}
From the *Public Health Laboratory, Glan Clwyd Hospital, Rhyl, Clwyd, Wales, and the †School of Pharmacy, Liverpool Polytechnic, Liverpool
\end{abstract}

SUMMARY Cryptosporidium spp is now widely accepted as a cause of gastroenteritis. Various methods have been applied to detect oocysts in faeces, but the difficulties of discriminating between non-cryptosporidial bodies, acid fast bodies like cryptosporidia, and cryptosporidia remain. A simple examination in two stages, suitable for routine use is described, using auramine phenol and carbol fuchsine for screening and a modified Ziehl-Neelsen staining method for confirmation. A further method, using Jenner and Giemsa stains, is of value for confirmation of identity, especially where fluorescence microscopy is unavailable. A modification of the formolether method of concentration is also described. Immunofluorescence and thin section electron microscopy provide definitive identification. Vomiting can be an important clinical feature of gastroenteritis, and the first description of oocysts in vomit is reported. Preliminary findings, after more than two years of study show that Cryptosporidium is an important pathogenic agent in gastroenteritis, confirm the increased incidence in children, and suggest a possible seasonal trend.

The coccidian protozoan parasite Cryptosporidium sp is now widely accepted as a cause of acute gastroenteritis. In some normal subjects the symptoms may be both severe and persistent, while in immunocompromised patients the infection may be life threatening.' Various methods have been recommended for studying cryptosporidia using light and transmission electron microscopy. These vary from the examination of wet films to negative staining by transmission electron microscopy. Since beginning our study early in 1983 we have supplied many laboratories with positive material and guidance, and in this paper we make recommendations for the routine diagnostic examination of faecal samples. A comparison of the methods studied has shown that the fluorescence stain described, together with modified formol-ether concentrations when appropriate, are significantly more sensitive than other methods $(p<0.001)$.

\section{Material and methods}

WET FILM: DIRECT EXAMINATION OF FAECAL MATERIAL

Jokipii $e t \boldsymbol{a l}^{2}$ and $\mathrm{Ma}$ and Soave ${ }^{3}$ recommended preliminary screening by the use of wet preparations. We found this method to be insensitive and not particularly helpful, although it may be helpful for detecting cysts or ova of other parasitic species that may also be present.

Accepted for publication 22 May 1985

\section{STAINING}

The use of Romanowsky stain to show endogenous stages in gut mucosa smears was first described by Tyzzer. ${ }^{4}$ This was extended to the detection of oocysts in smears of cattle faeces by Pohlenz et al $^{5}$ and in man by Tzipori et al. ${ }^{6}$ The method is relatively insensitive but still retains a useful role as an additional technique in cases of doubtful morphology. We prefer a combination of Jenner and Giemsa stains, which we use in an automatic slide staining apparatus (Shandon). Smears are placed in racks in the following reagents for five minutes for each stage: methanol 64 over proof $\times 2$; Jenner stain (BDH: diluted 1:6 in Sorensen's buffer pH 6.8) $\times 2$; Giemsa stain (BDH: diluted 1:10 in Sorensen's buffer) $\times 2$; Sorensen's buffer pH $6 \cdot 8$.

Cryptosporidium oocysts stain blue to azure, often with a crescentic pattern; about four to six red or purple dots may be seen, and there may be a clear halo surrounding the oocyst resulting from shrinkage.

\section{ZIEHL-NEELSEN METHOD}

A modified cold Ziehl-Neelsen method was first described by Henriksen and Pohlenz. ${ }^{7}$ Further modifications have now been described. ${ }^{8-10}$ The method is widely used, and we recommend the following procedure. Moderately thick faecal smears dried in air placed in multislide carriers for fixation and staining in batches of up to 16 slides in troughs as 
follows: methanol fixation, three minutes; strong carbol fuchsine ${ }^{11}$ (Paramount Reagents, Liverpool), 15 minutes, followed by thorough rinsing; minimal decolourisation in $1 \%$ hydrochloric acid in alcohol for 10-15 seconds, followed by rinsing; counterstain in $0.4 \%$ malachite green for 30 seconds; rinse well and dry in air.

Oocysts present as round objects, usually $4-5 \mu \mathrm{m}$ in diameter, with some degree of red staining of the internal structure, varying from an amorphous red mass filling the oocyst to obvious, multiple, crescentic, sporulated forms. In addition, highly refractile thick walled bodies may sometimes be seen, often unstained, which are possibly empty zygote cases rather than oocysts. Although these are often empty, they may sometimes contain an oocyst. The degree and proportion of staining of the oocysts varies, and holes may sometimes be apparent in the smear where oocysts have detached themselves. The appearance of unstained oocysts is, however, characteristic, and in practice this does not present a problem. A much higher proportion of oocysts appear to stain by auramine phenol using fluorescence microscopy.

\section{Fluorescence staining}

This has been reported by several workers. ${ }^{38} 12$ Most diagnostic microbiological laboratories have access to fluorescence microscopy, and the following novel modification first described by Casemore et al ${ }^{10}$ combines auramine phenol staining as previously described, ${ }^{11}$ with negative staining by strong carbol fuchsine as described by Heine ${ }^{13}$ in a simple two step procedure suitable for rapid screening of large numbers of samples.

\section{AURAMINE AND CARBOL FUCHSINE}

1 Thick faecal smears dried in air were placed in multislide carriers into a trough of auramine-phenol, stained for five minutes, then rinsed in tap water. 2 The smears were immersed briefly (five to 10 seconds) in strong carbol fuchsine, rinsed, and dried.

Total handling time for staining 16 slides was two to three minutes. Slides were examined using fluorescence microscopy at low magnification. Cryptosporidia appear as very characteristic brightly fluorescent discs against a dark red background. Positive specimens may be re-examined at high power by immersion in oil or in doubtful cases the object may be located by vernier reading and the slide re-examined after overstaining by the modified Ziehl-Neelsen technique. Doubtful scanty positive results may be checked after concentration of the specimen.

\section{Concentration methods}

Faeces received from acutely ill patients usually contain sufficient numbers of cysts, obviating the neces- sity for concentration methods. However, the examination of specimens from close family con- $\underline{0}$ tacts, cases in which diagnosis has been delayed, and follow up specimens from patients who have reco- $\stackrel{P}{+}$ vered merits the use of such techniques. A widely믐 reported method is that of sucrose flotation as described by Sheather in $1923^{14}$ : this method has $\frac{}{\sqrt{3}}$ several drawbacks, including interference with stain- $\stackrel{\mathbb{Q}}{\circledR}$ ing properties and adhesion of samples to the slide. We prefer a modification of the method of Allen and $\vec{P}$ Ridley. ${ }^{15}$ Some workers have failed to obtain satisfactory results with the formol-ether method, which $\vec{\omega}$ may have resulted from a failure to realise that the characteristics of cryptosporidial oocysts differ from? those of the parasite forms for which the method $\omega_{\infty}$ was originally devised. We would advocate the following new modification:

1 Fluid specimen of faeces, $0.5 \mathrm{ml}$, (or equivalent $\vec{\omega}$ of solid stool) is emulsified in about $3 \mathrm{ml}$ of $10 \%$ v formalin in water in a glass universal container using 음 a vortex mixer (with initial breaking up with anapplicator stick if necessary). Add $3 \mathrm{ml}$ ether and shake vigorously for 30-40 seconds.

2 Make up to about $15 \mathrm{ml}$ with $10 \%$ formalin, remix, and pour through a 40 mesh gauze sieve (Endecotts Ltd, London: certified test sieve 3 inches $\overrightarrow{ }$ ASTM, $425 \mu \mathrm{m}$ ) into a glass conical centrifuge tube्g. $\infty$

3 Centrifuge by setting the regulator to $1000 \mathrm{rpm}$. (450 RCF) and spin for half to one minute at thiss speed. Using a plastic disposable bulb pipette, carefully pass this down the side of the ether or debriso layer and remove the column fluid to a second tube.? Top up with formol water. (The deposit may be used $\stackrel{\mathbb{Q}}{\circ}$ to prepare wet films for examination for other ova $\overrightarrow{0}$ and cysts if required.)

4 Centrifuge at $3000 \mathrm{rpm}$ (1000 RCF) for five to 10 minutes depending on the viscosity of the specimen. The deposit is used to make a smear stained in the usual way.

\section{Electron microscopy}

The appearance of oocysts after negative staining of faecal material for the detection of viruses is quite characteristic, although the insensitivity of the method in terms of sample size makes the technique $\frac{7}{0}$ inappropriate for routine use, even where electron microscopy facilities are available. Thin sections of $N$ possible oocysts in faeces may be useful in providing definitive identification (Fig. 1).

\section{Results}

Fig. 2 shows a comparison of concentration $\stackrel{\oplus}{\rightleftharpoons}$ methods: the modified formol ether method is the 0 most sensitive. A comparison of the same methods, $\stackrel{\vec{P}}{\vec{P}}$ but staining by two different procedures (Ziehl- $\stackrel{\square}{\Omega}$ Neelsen and auramine and carbol fuchsine) showed $\stackrel{\mathbb{Q}}{\varrho}$ 


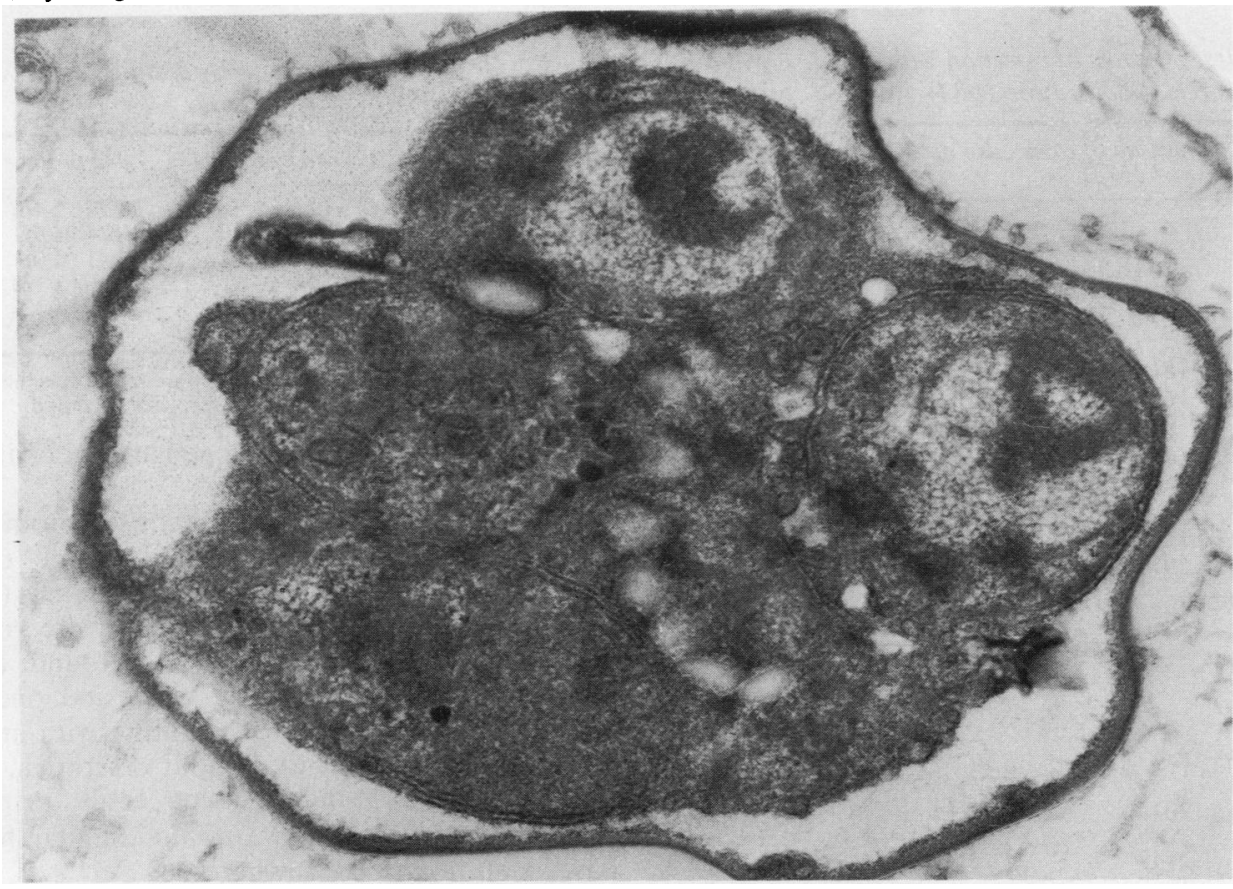

Fig. 1 Fresh faeces were suspended in agarose, fixed, and sectioned using a diamond knife. Oocyst contains four partially developed sporozoites and residual cytoplasmic mass. $\times 40000$.

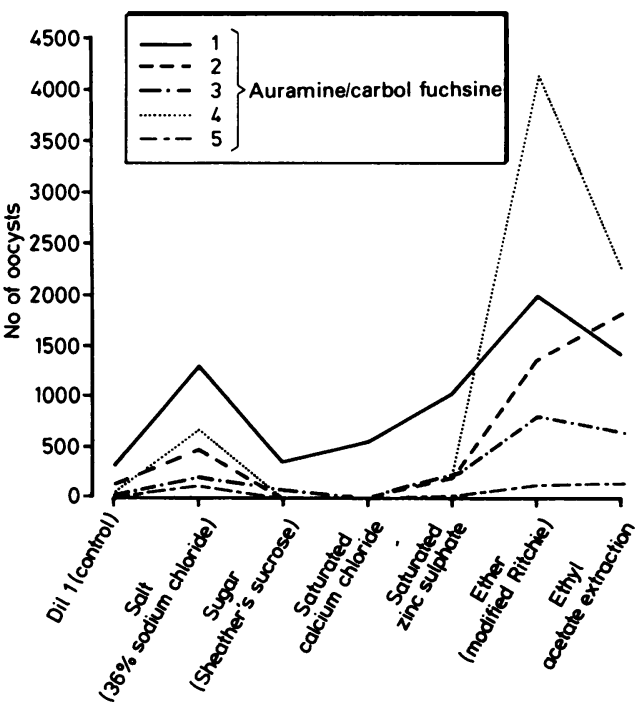

Fig. 2 Standardised smears prepared from concentrates. Statistical analysis was carried out (Dec 20 computer) using $\chi^{2}$ test with the null hypothesis and Yates's correction where appropriate. Results showed a significantly better performance by the modified ether method described $(p<$ $0.001)$. Sodium chloride gave the best results for flotation methods.

a significantly better result with the auramine or carbol fuchsine stain (Fig. 3). Results may vary according to the consistency of the stool, a finding also supported by $\mathrm{P} \mathrm{Ma}$ (personal communication).

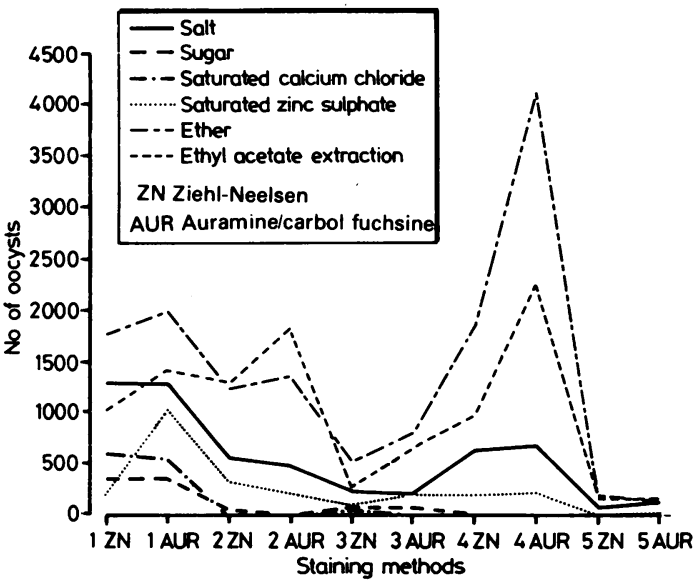

Fig. 3 Same specimens were subjected to identical tests, but duplicate smears were prepared and stained by modified Ziehl-Neelsen method; and auramine/carbol fuchsine. Results showed that the auramine/carbol fuchsine method performed significantly better than the Ziehl-Neelsen method $(p<0.001)$.

During two years of study over 3000 specimens were examined from a diverse population of patients, yielding more than 60 positive cases. Examination covered the most commonly recognised pathogens. Tables 1 and 2 show the results of investigations covering the first 50 positive cases. Overall, reports show that Cryptosporidium is found 
Table 1 First 50 cases of infection with cryptosporidium obtained (March 1983 to June 1984)

\begin{tabular}{|c|c|c|c|}
\hline Date & $\begin{array}{l}\text { Total no of cases } \\
(n=2573)\end{array}$ & \multicolumn{2}{|c|}{ No positive Age and Sex } \\
\hline $\left.\begin{array}{c}\text { 1983: } \\
\text { March } \\
\text { April } \\
\text { May }\end{array}\right\}$ & 70 (selected) & $\left\{\begin{array}{l}0 \\
0 \\
1\end{array}\right.$ & $\begin{array}{l}\text { M } 0 \\
\text { F } 9 / 12\end{array}$ \\
\hline June & 181 (unselected) & 0 & $\begin{array}{l}\text { M } 0 \\
\text { F } 0\end{array}$ \\
\hline July & 154 & 5 & $\begin{array}{l}\text { M 1, 5, } 12 \\
\text { F } 8,8\end{array}$ \\
\hline August & 183 & 1 & $\begin{array}{l}\text { M } 0 \\
\text { F } 32\end{array}$ \\
\hline September & 238 & 7 & M $1,2,9,26$ \\
\hline October & 201 & 4 & M 35 \\
\hline November & 183 & 0 & $\begin{array}{l}\text { MO } \\
\text { F } 0\end{array}$ \\
\hline December & 139 & 1 & $\begin{array}{l}\text { M } 0 \\
\text { F } 7\end{array}$ \\
\hline $\begin{array}{l}\text { 1984: } \\
\text { January }\end{array}$ & 149 & 0 & $\begin{array}{l}\text { M } 0 \\
\text { F } 0\end{array}$ \\
\hline February & 204 & 3 & $\begin{array}{l}\text { M } 1,1,18 \\
F_{0}\end{array}$ \\
\hline March & 214 & 9 & $\begin{array}{l}\text { M } 2,4,6,28,36, \\
37 \\
\text { F } 1,35,89\end{array}$ \\
\hline April & 218 & 12 & $\begin{array}{l}M 11 / 2,2,4,9,10 \\
\text { F } 8 / 12,3,6,8,19,28\end{array}$ \\
\hline May & 210 & 3 & $\begin{array}{l}\text { M } 7,16 \\
\text { F } 30\end{array}$ \\
\hline June & 229 & 4 & $\begin{array}{l}\text { M 7, } 28 \\
\text { F 4,9 }\end{array}$ \\
\hline Totals & 2573 & 50 & $28 \mathrm{M}: 22 \mathrm{~F}$ \\
\hline
\end{tabular}

No for $0-15(969), \geqslant 16(1333)$.

Age not known (271).

Table 2 League table of faecal pathogens (May 1983 to June 1984)

\begin{tabular}{|c|c|c|}
\hline Pathogen & No positive (\%) & $\begin{array}{l}\text { Total No of positives } \\
\text { expressed as \% }\end{array}$ \\
\hline $\begin{array}{l}\text { Campylobacter } \\
\text { Rotavirus } \\
\text { Cryptosporidium } \\
\text { Salmonella }\end{array}$ & $\begin{array}{r}117(27 \cdot 7) \\
84(19 \cdot 9) \\
50(11 \cdot 8) \\
48(11 \cdot 4)\end{array}$ & $\begin{array}{l}4 \cdot 5 \\
3 \cdot 3 \\
1 \cdot 9 \\
1.9\end{array}$ \\
\hline $\begin{array}{l}\text { Adenovirus (electron } \\
\text { microscopy) }\end{array}$ & $38(9 \cdot 0)$ & $1 \cdot 5$ \\
\hline $\begin{array}{l}\text { Enteropathogenic } \\
\text { Escherichia coli } \\
\text { Giardia lamblia } \\
\text { Shigella sonnei } \\
\text { Other bacteria } \\
\text { Other viruses } \\
\text { Total positive } \\
\text { Total examined }\end{array}$ & $\begin{array}{c}26(6 \cdot 2) \\
25(6.0) \\
15(3.2) \\
12(2 \cdot 8) \\
8(1 \cdot 9) \\
423 \\
2573\end{array}$ & $\begin{array}{r}1.0 \\
1.0 \\
0.6 \\
\\
\\
16.4\end{array}$ \\
\hline
\end{tabular}

Low level of positives overall reflects the inclusion of samples from non-infective diarrhoeas, some routine samples, and a high proportion of samples from adults.

in about $2 \%$ of all specimens examined, although among children the incidence appears to be about $4 \%$ (Table 3). In our laboratory it is the third most
Table 3 Occurrence of cryptosporidium by age 1983-4 (published reports)

\begin{tabular}{lcc}
\hline Source & No examined & No positive (\%) \\
\hline World wide* $^{*}$ & 11067 & $272(2 \cdot 46)$ \\
Children $\dagger$ & 2531 & $124(4 \cdot 9)$ \\
Adults $\dagger$ & 2026 & $41(2 \cdot 0)$ \\
United Kingdom* & 6580 & $140(2 \cdot 13)$ \\
Children ${ }^{\dagger}$ & 1363 & $59(4 \cdot 32)$ \\
Adults $\dagger$ & 1739 & $35(2 \cdot 01)$ \\
\hline
\end{tabular}

*All patients including those whose ages were not specified.

tAll patients including those whose ages were specified.

frequently encountered pathogen after rotavirus and Campylobacter.

Vomiting is often a predominant symptom. Cryptosporidium was found in the vomit of one patient from whom we examined specimens (a child $\vec{N}$ admitted to hospital as a result of severe vomiting and diarrhoea). In addition, we found cryptosporidia in the stool of one child and one adult patient who complained of vomiting with anorexia and abdominal pain but without diarrhoea. Mixed infections were found in some cases, principally with Campylobacter and Giardia. Similar findings have been reported elsewhere. ${ }^{16} 17$

No particular seasonality has been noted, although an outbreak occurred in this area during $\overrightarrow{0}$ March and April 1984 in which campylobacter wag or also often isolated. ${ }^{16}$ During both winters there wh. a low prevalence with an increase again in the spring of 1985.

\section{Discussion}

No staining method for cryptosporidia is completely $\overrightarrow{\vec{\partial}}$ effective, a view shared by $\mathbf{P}$ Ma (personal com- 3 munication). The appearance of cryptosporidial oocysts in faeces, however, is generally sufficiently? typical for there to be little difficulty in identifying the organism in most cases. On the other hand, the inexperienced may be confused by a variety of objects resembling oocysts in general appearance, whichever staining method is applied. In addition, cryptosporidia have been described that are larger than the usual size range of 3-6 $\mu \mathrm{m}$. Triffit, ${ }^{18}$ Bearup, ${ }^{19}$ and Dubey and Pande ${ }^{20}$ described what $\frac{T}{O}$ were claimed to be cryptosporidia in snakes, dingoes, and jungle cats, respectively, which were con- $\mathcal{N}$ siderably larger $(7-17 \mu \mathrm{m})$. Although not yet reported from other species, including man, we N found similar large objects like cryptosporidia in $\mathrm{\omega}$ both environmental and occasionally human specimens.

Objects comparable in size to cryptosporidia may also be found, but they have different internal struc-? tures or staining features. In any doubtful case we apply immunofluorescence staining by a method to $\frac{\mathrm{O}}{\mathbb{D}}$ be described in detail elsewhere, together with 


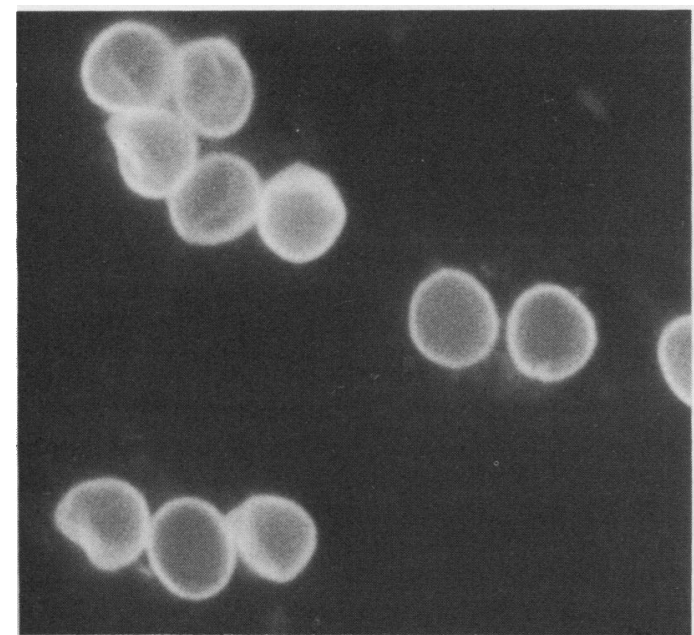

Fig. 4 Cryptosporidium oocysts stained by

immunofuorescence using convalescent human serum and an antihuman globulin/fuorescine isothiocyanate conjugate. $\times 2000$.

details of serological diagnosis. Briefly, the specimen is dispensed on to the wells of a microscope slide coated with telfon, air dried, and fixed in cold acetone for five minutes. A pool of high titre IgA positive convalescent human sera is then used at a predetermined titre in a sandwich technique using an antihuman fluorescein isothiocyanate conjugate against the IgA fraction (Wellcome Reagents) used at optimal dilution (Fig. 4).

Our own continuing study, together with reports from elsewhere ${ }^{21-23}$ confirm earlier observations from this laboratory ${ }^{24} 25$ that the infection is not uncommon, especially in children, and should not be assumed to be a zoonosis as it occurs in the urban environment, especially in children in day care centres. It may also be found as a cause of travellers' diarrhoea. ${ }^{26}$ In addition to probable person to person spread, local studies ${ }^{1628}$ and evidence from elsewhere $^{27}$ suggest that raw milk, sausage, and environmental sources may all have a role in transmission.

We thank Dr FB Jackson, director, the staff of this laboratory and of the Moredun Institute, Edinburgh, for help and encouragement, Mrs G Stringfellow for secretarial help, and Dr A Curry, Public Health Laboratory and Department of Histopathology, Withington, for help with electron microscopy.

This work forms part of a project for a higher degree (DPC) and FIMLS project (MA) at the Liverpool Polytechnic School of Pharmacy.

\section{References}

' Anonymous. Cryptosporidiosis [editorial]. Lancet 1984;i:492-3. ${ }^{2}$ Jokipii L, Pohjola S, Jokipii AMM. Cryptosporidium: a frequent finding in patients with gastrointestinal symptoms. Lancet 1983;ii:358-61.

${ }^{3}$ Ma P, Soave R. Three-step stool examination for cryptosporidiosis in 10 homosexual men with protracted watery diarrhea. J Infect Dis 1983;5:824-8.

4 Tyzzer EE. Extracellular coccidium, Cryptosporidium muris (gen et sp nov), of the gastric glands of the common mouse. J Med Res 1910;23:487-509.

s Pohlenz J, Moon HW, Cheville NF, Bemrick WJ. Cryptosporidiosis as a probable factor in neonatal diarrhea of calves. J Am Vet Med Assoc 1978;172:452-7.

- Tzipori S, Angus KW, Gray EW, Campbell I. Vomiting and diarrhea associated with cryptosporidial infection. $N$ Engl $J$ Med 1980;303:818.

${ }^{7}$ Henriksen SA, Pohlenz JFL. Staining of cryptosporidia by a modified Ziehl-Neelsen technique. Acta Vet Scand 1981;22: 594-6.

' Garcia LS, Bruckner DA, Brewer TC, Shimizu RY. Techniques for the recovery and identification of Cryptosporidium oocysts from stool specimens. J Clin Microbiol 1983;18:185-90.

'Bronsdon MA. Rapid dimethyl-sulfoxide-modified acid-fast stain of Cryptosporidium oocysts in stool specimens. J Clin Microbiol 1984; 19:952-3.

${ }^{10}$ Casemore DP, Armstrong M, Jackson B. Screening for Cryptosporidium in stools. Lancet $1984 ; \mathrm{i}: 734-5$.

"Cruickshank R, Duguid JP, Marmion BP, Swain RH. Medica microbiology. Vol II. The practice of medical microbiology. London: Churchill Livingstone, 1975.

${ }_{12}$ Nichols G, Thom BT. Screening for Cryptosporidium in stools. Lancet 1984; 735.

${ }^{13}$ Heine J. Eine einfache Nachweismethode fur Kryptosporidien im Kot. Zentrollb Veterinurmed (A) 1982;29:324-7.

14 Sheather AL. The detection of intestinal protozoa and mange parasites by a flotation technique. Journal of Comparative Pathology and Therapeutics 1923;36:266-75.

is Allen AVH, Ridley DS. Further observations on the formolether concentration technique for faecal parasites. Technical Methods 1970; 23:545-6.

${ }^{16}$ Casemore DP, Jackson FB, Douce D, Jessop EG. Cryptosporidium plus campylobacter: an outbreak in a semi-rural population. J Hyg (in press).

${ }^{17}$ Wolfson JS, Hopkins CC, McCarth DM. An association between Cryptosporidium and Giardia in stools. $N$ Engl $J$ Med 1984;311:788.

18 Triffit MJ. Observations on two new species of coccidia parasitic in snakes. Protozoology 1925;1:19-26.

${ }^{19}$ Bearup AJ. The coccidia of carnivores in Sydney. Aust Vet $J$ 1954;30: $185-7$.

${ }^{20}$ Dubey JP, Pande BP. Observations on the coccidian oocysts from Indian jungle cat (Felis chaus). Ind $J$ Microbiol 1963; 13: $103-8$.

${ }^{21}$ Hunt DA, Shannon R, Palmer SR, Jephcott AE. Cryptosporidiosis in an urban community. Br Med J 1984; 289:814-6.

22 Wright PA, Harrison JM, Byrom I. Cryptosporidiosis. Br Med J 1984; 289: 1148 .

${ }^{23}$ Alpert G, Bell LM, Kirkpatrick CE, et al. Cryptosporidiosis in a day care center. $N$ Engl J Med 1984;311:860-1.

24 Casemore DP, Jackson B. Sporadic cryptosporidiosis in children. Lancet 1983;ii: 679.

${ }^{25}$ Casemore DP, Jackson FB. Hypothesis: cryptosporidiosis in human beings is not primarily a zoonosis. Journal of Infection 1984;9:153-6.

${ }^{26}$ Soave R, Ma P. Cryptosporidiosis-travellers' diarrhoea in two families. Arch Intern Med 1985; 145:70-2.

${ }^{27}$ Isaacs D, Hunt GH, Philips AD, Price EH, Raafat F, WalkerSmith JA. Cryptosporidiosis in immunocompetent children. $J$ Clin Pathol 1985;38:76-81.

28 Casemore DP. Cryptosporidiosis. J Environ Health 1985;93:5.

Requests for reprints to: Dr DP Casemore, Public Health Laboratory, Ysbyty Glan Clwyd, Bodelwyddan, Rhyl, Clwyd, Wales LL18 5UJ. 